\title{
THE ACCELEROMETRIC NETWORK OF THE INDES-MUSA PROJECT IN THE KALOCHORI AREA: CONFIGURATION, DOCUMENTATION AND PRELIMINARY DATA INTERPRETATION
}

\author{
Rovithis Emm. ${ }^{1}$, Makra K. ${ }^{1}$, Savvaidis A. ${ }^{1}$ and Kirtas Emm. ${ }^{2}$ \\ ${ }^{1}$ Institute of Engineering Seismology and Earthquake Engineering EPPO-ITSAK, Thessaloniki, \\ Greece,rovithis@itsak.gr,makra@itsak.gr,alexandros@itsak.gr \\ ${ }^{2}$ Technological Educational Institute of Central Macedonia, Serres, kirtas@teiser.gr
}

\begin{abstract}
A network of seven accelerometric stations on both ground surface and structures has been recently installed, as part of a multi-sensor network for monitoring seismic motion and ground subsidence in the broader area of Kalochori, west of Thessaloniki in Northern Greece, within the INDES-MUSA project. This network includes ground installations within the urban area, structural stations on top of structures and a freefield station away from the building stock. The documentation of stations is presented including shear wave velocity profiles of the subsoil at each location. A set of thirtynine earthquakes recorded so far by the accelerometric network is reported, followed by data processing procedures performed in the acquired waveforms. Comparisons of the processed earthquake recordings are presented referring to (a) the urban ground and the free-field stations in terms of peak ground acceleration, indicating amplification trends of ground motion, and (b) the structural and the nearby urban ground stations by means of top-to-base ratios in the frequency domain, towards a preliminary identification of the fundamental vibrational characteristics of the instrumented structures. The processed acceleration data are available through the INDES-MUSA Web-GIS portal.
\end{abstract}

Keywords: seismic response of structures; multi-sensor monitoring; earthquake recordings; soil-structure interaction; data dissemination.

\section{Пєрі́ $\eta \psi \eta$}

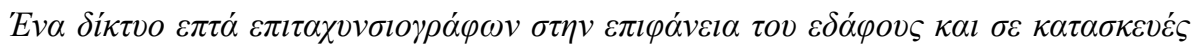

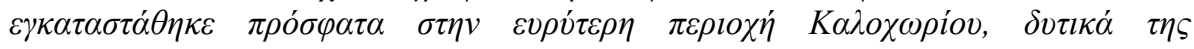

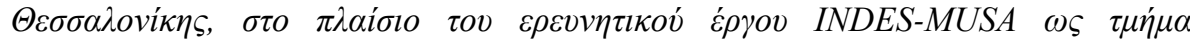

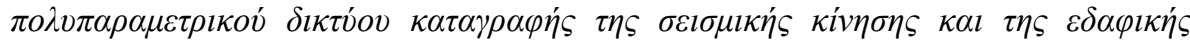

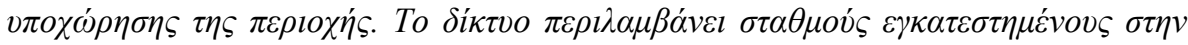

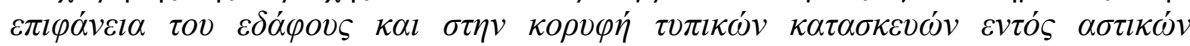

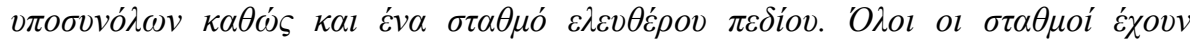

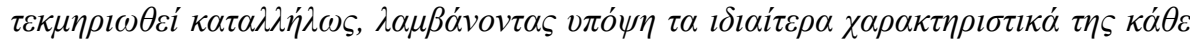

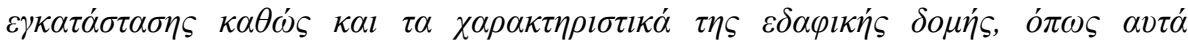

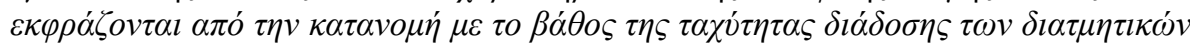

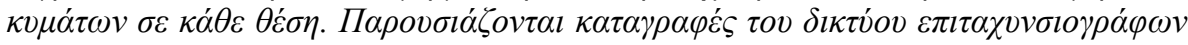

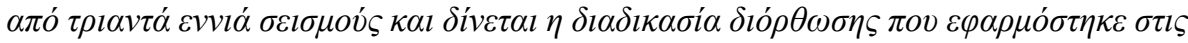




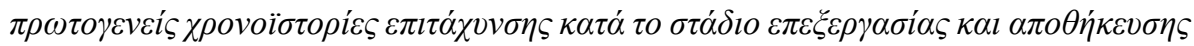

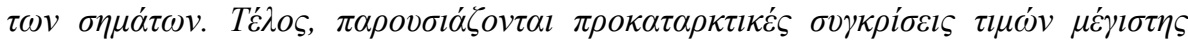

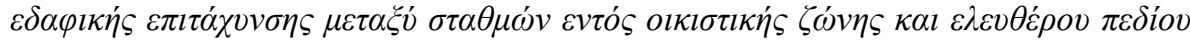

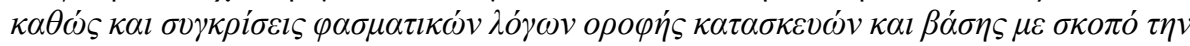

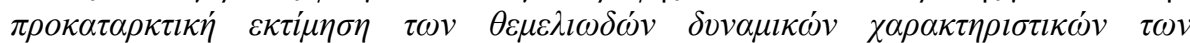

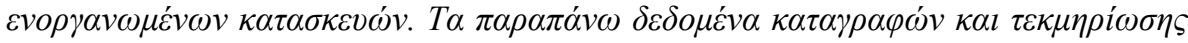

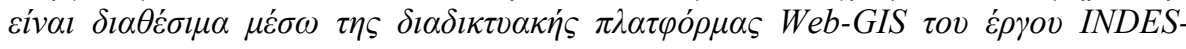
MUSA.

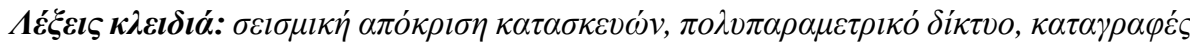

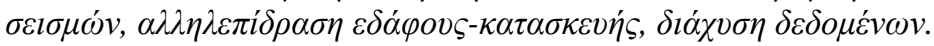

\section{Introduction}

Monitoring of earthquake ground motion and seismic response of structures in a densely built urban environment is strongly related to the interplay between structural and soil response during earthquake shaking. In this regard, contamination of earthquake recordings by structural response or soil-structure interaction of the built environment has been reported in relevant studies (Gueguen et al., 2002; Bard et al., 2007). It is therefore critical to record ground motions that represent the actual ground shaking imposed on structures as part of an urban area (Chen et al., 2010; Taborda and Bielak, 2011). Reversely, the deployment of a dense accelerometric network within an urban site contributes to a large-scale assessment of seismic response of structures as affected by soil-structure interaction, thus effectively expanding the investigation from that of a single building - as is usually adopted in current design or analysis practice - to the level of urban environment.

Along these lines, a dense accelerometric network has been recently deployed in the broader urban area of Kalochori, west of Thessaloniki, as part of a multi-sensor network for monitoring seismic motion and ground subsidence within the INDES-MUSA project (www.indes-musa.gr). Besides accelerometric stations, the above multi-sensor network comprises of GNSS base stations, a tide gauge system, a spatially distributed temporal network of eighteen (18) mobile rover GNSS and periodic measurements of water level at thirty-three (33) inactive boreholes (Rovithis et al., 2014). Among the innovative features of the monitoring scheme is the implementation of airborne Light Detection And Ranging (LiDAR) missions to monitor surface topography changes and produce a $3 \mathrm{D}$ city model covering approximately $25 \mathrm{~km}^{2}$ of the area under investigation (Charalampopoulou $e t$ al., 2014). The permanent installations of the INDES-MUSA multi-sensor network are mapped in Figure 1 . The area is characterized by a complex urban environment including residential buildings and important civil infrastructures such as industries, tanks, power supply installations and lifeline networks. Four sub-areas of interest shown in Figure 1 were geographically defined, referring to a free-field zone away from the urban environment and three urban zones (i.e. the residential zone, the industrial zone and the tanks zone), allowing treatment of each urban sub-area as a homogenized unit with similar structural types and urban densities.

Evidence on the seismicity of the broader Kalochori region including the city of Thessaloniki is reported in Paradisopoulou et al. (2006). The area has experienced several destructive earthquakes (M6.2 to M7.5) during its 23 centuries of continuous history. The strong M6.5 earthquake of 20/06/1978 occurred at an epicentral distance of $30 \mathrm{~km}$ east of Thessaloniki causing fifty deaths, severe damages recorded at approximately $25 \%$ of the building stock and serious social-economic losses.

The INDES-MUSA accelerometric network includes stations on ground surface and on top of representative structures within each urban sub-zone and a free-field reference station. Following a detailed documentation of the installations, a data processing procedure is presented for the acceleration recordings that have been acquired so far from thirty nine earthquakes with epicentres in the Hellenic region. Comparisons of the processed recordings are reported between (a) the ground stations within each urban sub-zone and the free-field station in terms of peak ground acceleration and (b) the structural stations and the nearby urban ground stations by means of top-to-base ratios 
in the frequency domain. A Web-GIS service tool (http://indes-musa.gr/en/webgis) for the dissemination of the INDES-MUSA monitoring products and data has been designed to release the acquired processed acceleration recordings to interested end-users.

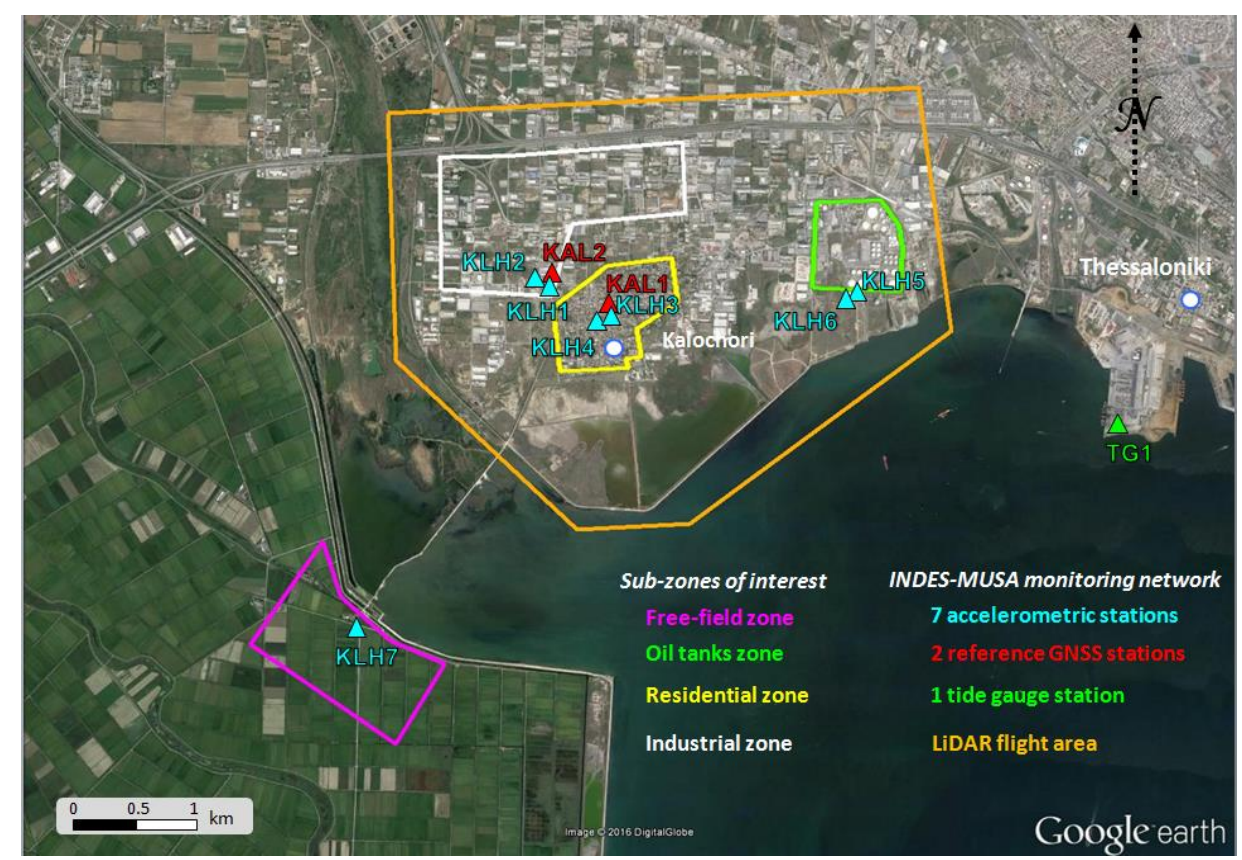

Figure 1 - The INDES-MUSA permanent monitoring network installed in the broader area of Kalochori and subdivision into four sub-zones of interest (Google Earth image).

\section{Accelerometric network of the INDES-MUSA project in the Kalochori area: Documentation of stations}

A pair of triaxial REFTEK 130-SMA high resolution (24bit) and absolute GPS time accelerometric stations is installed in each urban sub-zone corresponding to a "structural station" (denoted with "S") and an "urban reference station" (denoted with " $U F$ "), respectively, following the definitions given in COSMOS (2001). The former refers to an accelerometric station installed on the top of a representative structure of each urban sub-zone whereas the latter refers to a ground installation (either on open ground or in a small low-rise structure) within each urban sub-zone where minor contamination of earthquake recordings by the dynamic response of the housing building itself is anticipated. In this manner, a pair of " $S$ " - " $U F$ " accelerometric stations is installed in each urban sub-zone of the broader Kalochori area, allowing for the assessment of the instrumented structures natural period by means of structural top-to-ground base response ratios in the frequency domain (Faccioli et al., 1996; Meli et al., 1998; Celebi, 2003), as explained in the ensuing. The INDES-MUSA accelerometric network is complemented with a free-field station (denoted with " $F F$ ") installed on open ground at $3 \mathrm{~km}$ approximately away from the built environment.

The location of the seven stations composing the INDES-MUSA accelerometric network is shown in Figure 2 while the main features of each station are summarized in Table 1. It is noted that two accelerometric stations (KLH1 and KLH3) are collocated with GNSS reference stations. KLH5 station was mounted on top of the water tank through a steel base welded at the center of the tank roof whereas KLH7 station was founded on a small, partially embedded reinforced concrete slab of $70 \times 70 \mathrm{~cm}$ plan dimensions and $20 \mathrm{~cm}$ thickness, following the COSMOS (2001) guidelines. 


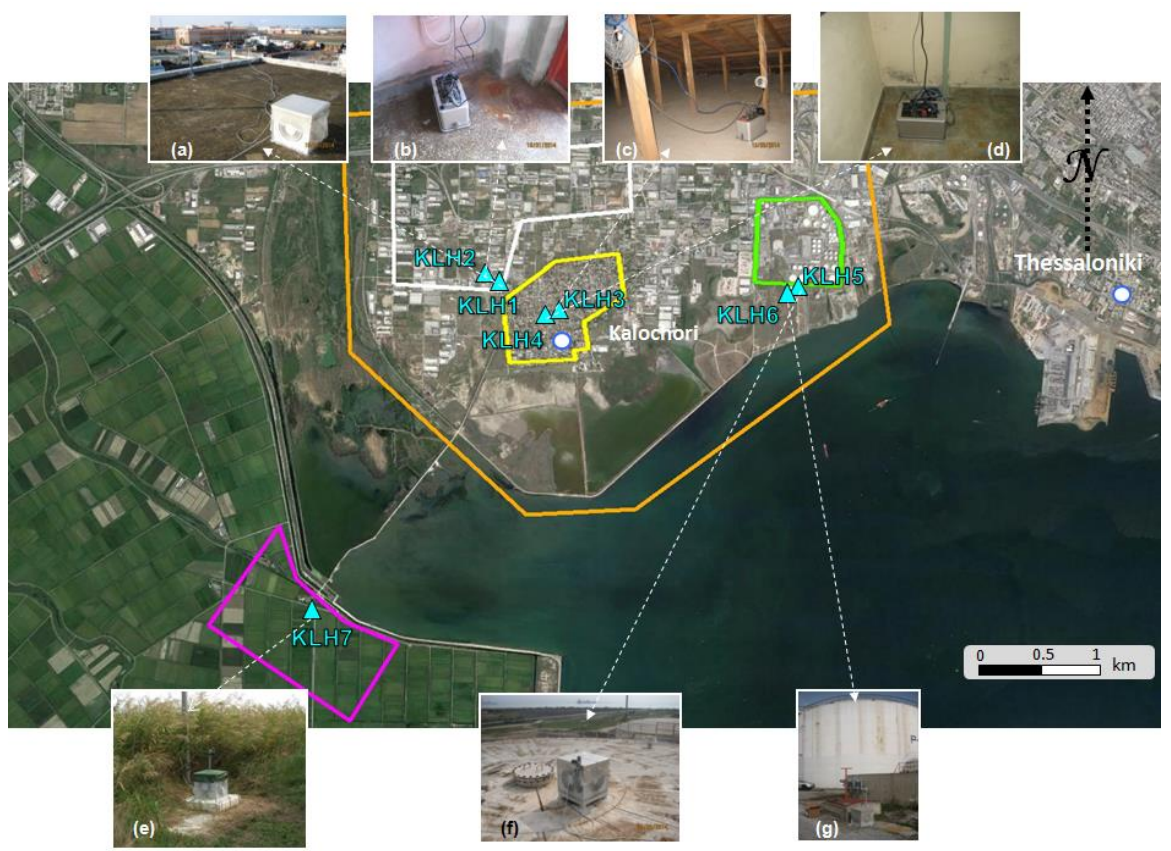

Figure 2 - Accelerometric stations in the broader Kalochori area: (a) KLH1 and (b) KLH2 stations in the industrial sub-zone (white polygon), (c) KLH3 and (d) KLH4 stations in the residential sub-zone (yellow polygon), (f) KLH5 and (g) KLH6 stations in the tanks sub-zone (green polygon) and (e) KLH7 station in the free-field zone (magenta polygon).

Table 1 - Main features of INDES-MUSA accelerometric network.

\begin{tabular}{|c|c|c|c|}
\hline $\begin{array}{l}\text { Accelerometric } \\
\text { station }\end{array}$ & $\begin{array}{l}\text { Sub-area of } \\
\text { investigation }\end{array}$ & $\begin{array}{l}\text { Type of } \\
\text { station* }\end{array}$ & Description of installation \\
\hline KLH1 & \multirow[t]{2}{*}{ Industrial } & $S$ & $\begin{array}{c}\text { On the roof slab of a 2-storey R/C building of } \\
\text { industrial type housing the municipal gymnasium of } \\
\text { Kalochori }\end{array}$ \\
\hline KLH2 & & $U F$ & $\begin{array}{c}\text { In a small warehouse close to the gymnasium } \\
\text { building }\end{array}$ \\
\hline KLH3 & \multirow{2}{*}{ Residential } & $S$ & $\begin{array}{l}\text { On the roof slab of a 2-storey stiff stone masonry } \\
\text { structure housing the Cultural Centre of Kalochori }\end{array}$ \\
\hline KLH4 & & $U F$ & $\begin{array}{l}\text { In a small warehouse close to the Cultural Centre of } \\
\text { Kalochori }\end{array}$ \\
\hline KLH5 & \multirow{2}{*}{ Oil tanks } & $S$ & $\begin{array}{c}\text { On the roof slab of a steel water tank owned by } \\
\text { EL.PE oil company }\end{array}$ \\
\hline KLH6 & & $U F$ & On open ground close to the water tank's base \\
\hline KLH7 & Free field & $F F$ & $\begin{array}{l}\text { On the ground surface at the other side of the } \\
\text { Kalochori bay, } 3 \mathrm{~km} \text { approximately away from the } \\
\text { urban area }\end{array}$ \\
\hline
\end{tabular}

The installation of the accelerometric stations was completed within the period $16^{\text {th }}$ of January 2014 to $13^{\text {th }}$ of March 2014, except KLH7, which was installed 6 months later (15 $5^{\text {th }}$ of September 2014). All the stations are oriented along the N-S direction and operate on a continuous-recording basis with real-time data transfer (except stations KLH5 and KLH6 where the recorded data is stored 
locally and collected on site) to the central INDES-MUSA data acquisition server hosted in the premises of EPPO-ITSAK in Thessaloniki.

\subsection{Accelerometric stations monographs}

With reference to geological aspects, the region of Kalochori constitutes a tectonic graben covered by Quaternary and Neogene deposits of large thickness, consisting mainly of marine and lacustrine sediments. According to Nikolaou and Nikolaidis (1987), these deposits extend to a depth varying from 150 to $400 \mathrm{~m}$ whereas deeper soil layers consist of Neogene deposits until 600-700m. Subsoil conditions at the sites of the INDES-MUSA accelerometric stations were further explored by in-situ geophysical Microtremor Array Method measurements. The latter were performed within each investigated sub-zone to obtain the distribution of shear wave propagation velocity $\left(\mathrm{V}_{\mathrm{s}}\right)$ with depth. The analysis of microtremor (ambient noise) data followed two main processing stages, namely the extraction of surface waves' dispersion curve (Figure 3a) using the frequency- wavenumber ( $\mathrm{f}-\mathrm{k}$ ) method (Lacoss et al., 1969; Capon, 1969; Horike, 1985; Kvaerna and Ringdahl, 1986; Okada, 2003) and the application of inversion methods for the estimation of the local 1D seismic wave velocity distribution (Figure 3b). In the approach adopted herein, the inversion of the surface waves' dispersion curve was based on a neighbourhood algorithm, which allows the incorporation of a priori information about the subsurface structure parameters (Wathelet et al., 2004; Wathelet, 2005). Following this procedure, the final shear wave velocity profiles were obtained for each sub-zone of interest (Figure 3c). Further details on the above geophysical field measurements may be found in Savvaidis et al. (2014). The above data was compiled in a monograph sheet for each accelerometric station where the following information is reported:

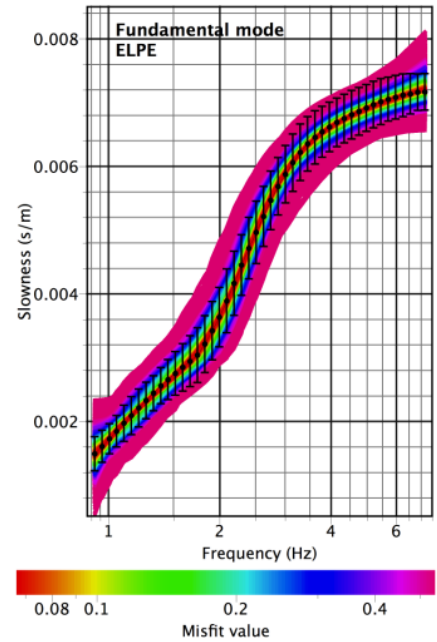

(a)

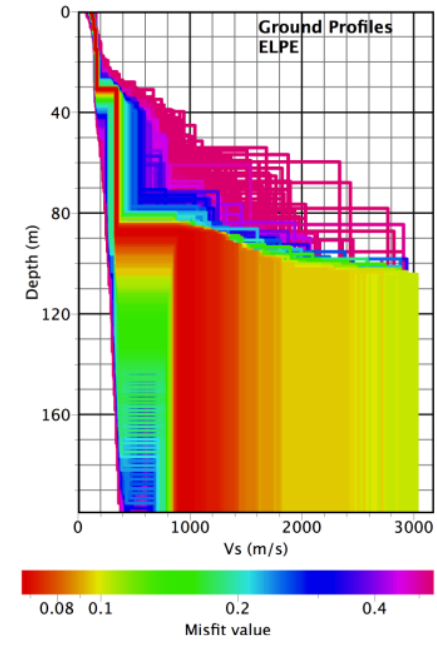

(b)

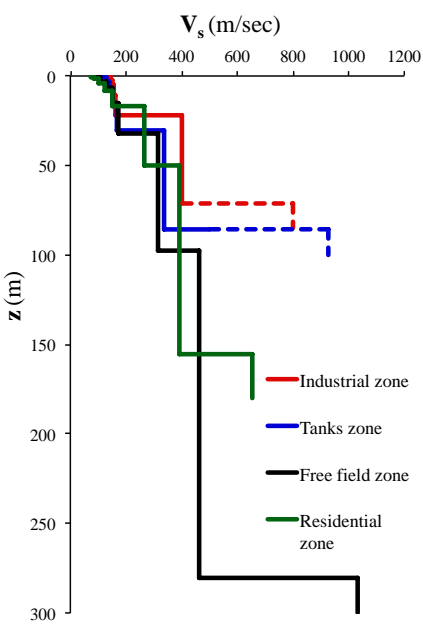

(c)

Figure 3 - (a) Dispersion curves for the earth models presented on the center plot with the corresponding dispersion curve (in black) as resulted from the processing of the data. (b) Inverted local 1D shear wave velocity profiles at station KLH6. The color scale denotes with red the earth models with the lowest misfit. (c) 1D shear wave velocity profiles (best solution based on lowest misfit values) for each sub-zone.

Code name of the accelerometric station, type of installation (i.e. " $S$ ", " $U F$ " or " $F F$ " type of station), sub-zone of interest where the station is installed, GPS coordinates of the station location, collocation with a GNSS base station (if available), type of data transfer (real-time through internet connection or collected on site), shear wave velocity profile until the depth of $30 \mathrm{~m}$, computed value of $\mathrm{V}_{\mathrm{s}, 30}$ based on the geophysical data, soil type according to EC8 based solely on the $\mathrm{V}_{\mathrm{s}, 30}$ value, surface geology as reported in IGME maps, brief description of the installation and photos taken 
during the installation of each station. All the stations monographs have been uploaded to the WebGIS service tool mentioned above. For instance, KLH7 station monograph may be found in http://195.251.49.58/apollo-portal/img/Monographs_Accel/KLH7.pdf.

\section{Recorded earthquake events}

During the period $16 / 01 / 2014$ to $26 / 07 / 2015$, acceleration recordings from thirty-nine (39) earthquakes (Figure 4) with magnitude (M) and epicentral distance (R) from the Kalochori residential area ranging between 2.7 to 6.2 and $11.1 \mathrm{~km}$ to $706.2 \mathrm{~km}$, respectively, were acquired by the INDES-MUSA accelerometric network. The corresponding (M)-(R) plot is also shown in Figure 4. Peak accelerations in the range of $1 \mathrm{mg}$ to $10 \mathrm{mgs}$ were recorded from the above earthquakes within the area under study.

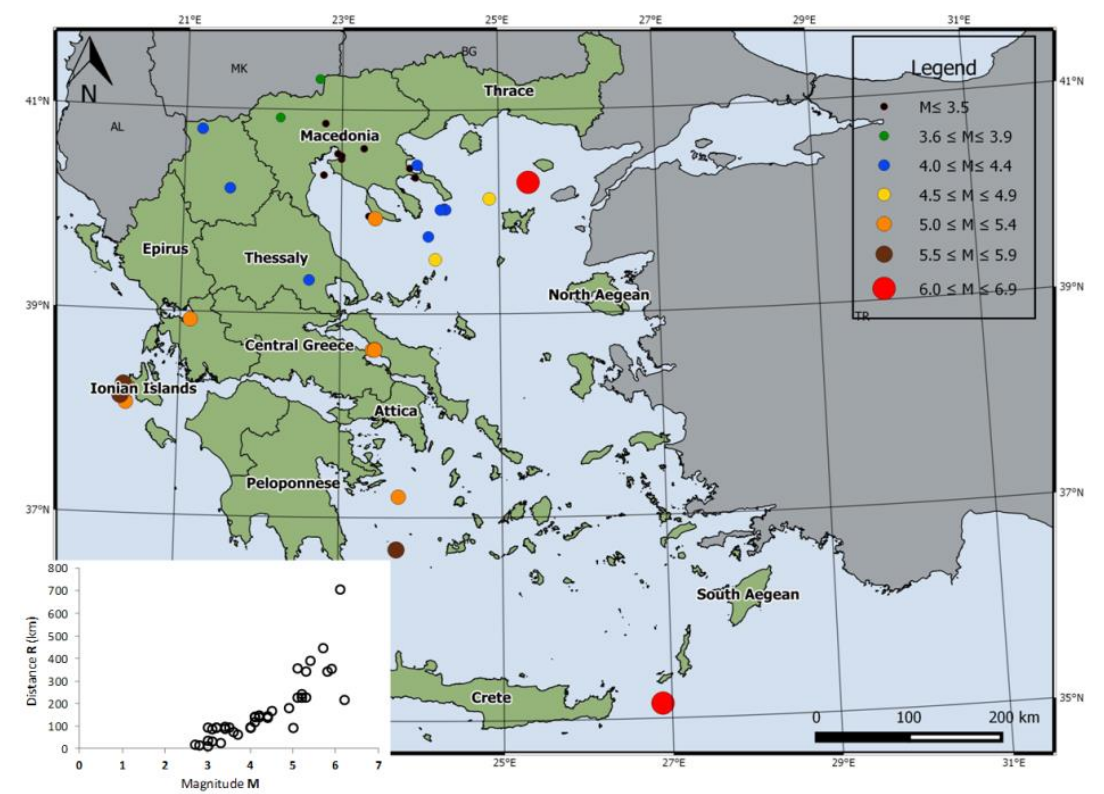

Figure 4 - Map of earthquake epicenters recorded from the INDES-MUSA accelerometric network during 16/01/2014 to 26/07/2015. The corresponding $(\mathrm{M})$-(R) plot is also shown.

Basic earthquake characteristics referring to the origin time, magnitude, epicenter coordinates, focal depth and distance of the epicentre from the Kalochori residential area are summarized in Table 2, based on seismological data from the Seismological Station of Aristotle University of Thessaloniki (http://geophysics.geo.auth.gr/ss/). Data availability from each accelerometric station and data processing features are also reported in Table 2. More specifically, the begin time (B_time) of the processed acceleration recordings was taken equal to the Origin Time (O.T.) for each earthquake event while the End Time (E_time) was defined by the Origin Time plus a pertinent time window covering the desirable waveform. The waveforms were baseline corrected and band-pass filtered by implementing the cut-off frequencies $\mathrm{C} 1$ and $\mathrm{C} 2$ mentioned in Table 2. An indicative comparison between unfiltered and filtered waveforms is shown in Figure 5. The complete set of recordings for the above time period is compiled in a database that includes 582 waveforms corresponding to 194 three-component recordings. Based on the ORFEUS-ESM database standards, the file names of the acceleration recordings follow the structure:

net_code.station_code.location_code.channel_code.date.time.processing_type.waveform_type.format. 
Table 2 - Seismological data for the earthquakes recorded from the INDES-MUSA network during the period $16 / 01 / 2014$ to $26 / 07 / 2015$.

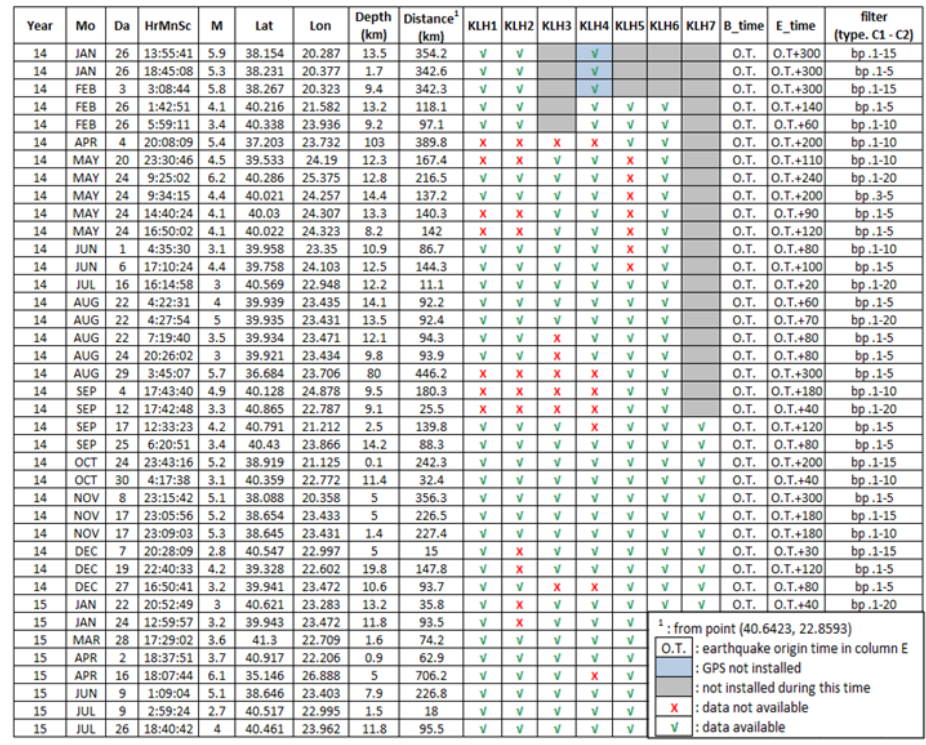

UNFILTERED WAVEFORMS: 20141207202809

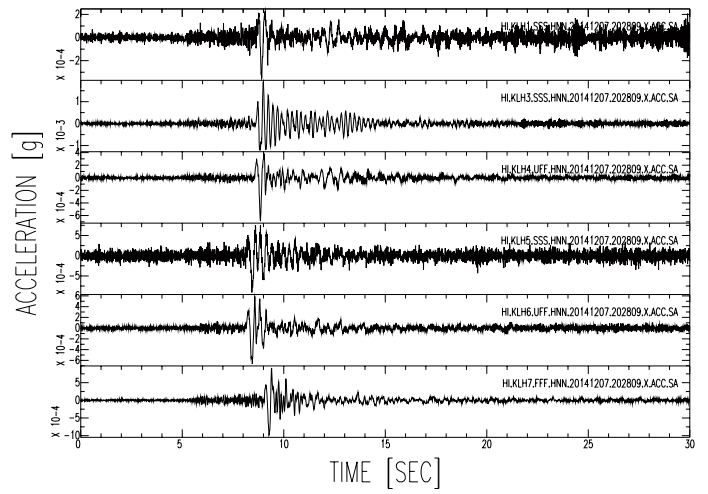

FILTERED WAVEFORMS: 20141207202809

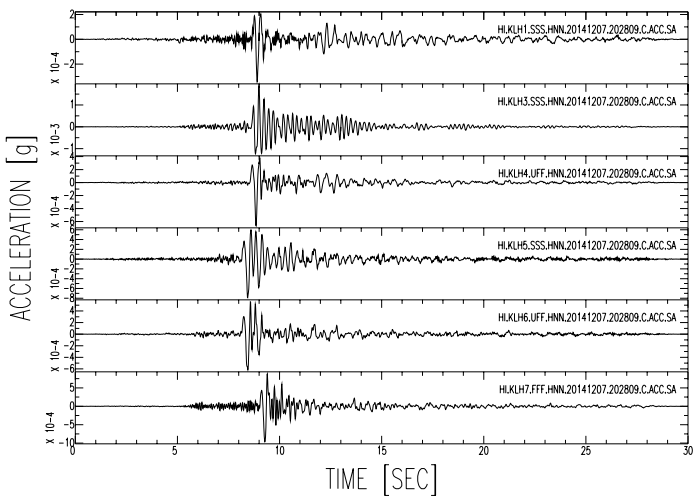

Figure 5 - Acceleration recordings processing: Comparison of pre- (left) and post- filtering (right) the NS component of acceleration time histories for the earthquake occurred on December 7, 2014 (20:28:09 GMT).

For example, the processed (C) acceleration time series (ACC) recorded at the seismic network of ITSAK (HI) installed at the top of the water tank (KLH5, SSS), N-S component (N), occurred on 2014-09-25 at 06:20:51 GMT in ASCII format (ASC), has the following name: HI.KLH5.SSS.HNN.20140925.062051.C.ACC.ASC

The processed acceleration waveforms have been uploaded to the Web-GIS platform (http://indesmusa.gr/en/webgis) along with the corresponding site information reported in the stations monographs mentioned above, as part of the INDES-MUSA research project outcomes at the disposal of the scientific community and interested end users. 


\section{Preliminary data interpretation}

Earthquake acceleration recordings acquired from the different types of installations (i.e. " $S$ ", " $U F$ " and " $F F$ " type) allow for some preliminary observations. Figure 6 shows peak ground acceleration ratios $\left(\mathrm{PGA}_{\mathrm{FF}} / \mathrm{PGA} \mathrm{UF}_{\mathrm{F}}\right)$ obtained from the free-field station (KLH7) recordings to urban reference station (KLH4) recordings in the residential sub-zone. The different group of columns in the plot refer to the N-S, the E-W and the vertical component of motion as recorded from nine earthquakes. Although the limited number of available recordings disallows generalized conclusions, it is observed that peak ground acceleration is systematically higher in the free-field zone with respect to the residential sub-zone, independently of the different earthquake characteristics. A similar but less pronounced trend was observed when $\mathrm{PGA}_{\mathrm{UF}}$ is obtained from the acceleration recordings of KLH2 and KLH6 urban reference stations in the industrial and tanks sub-zone, respectively.

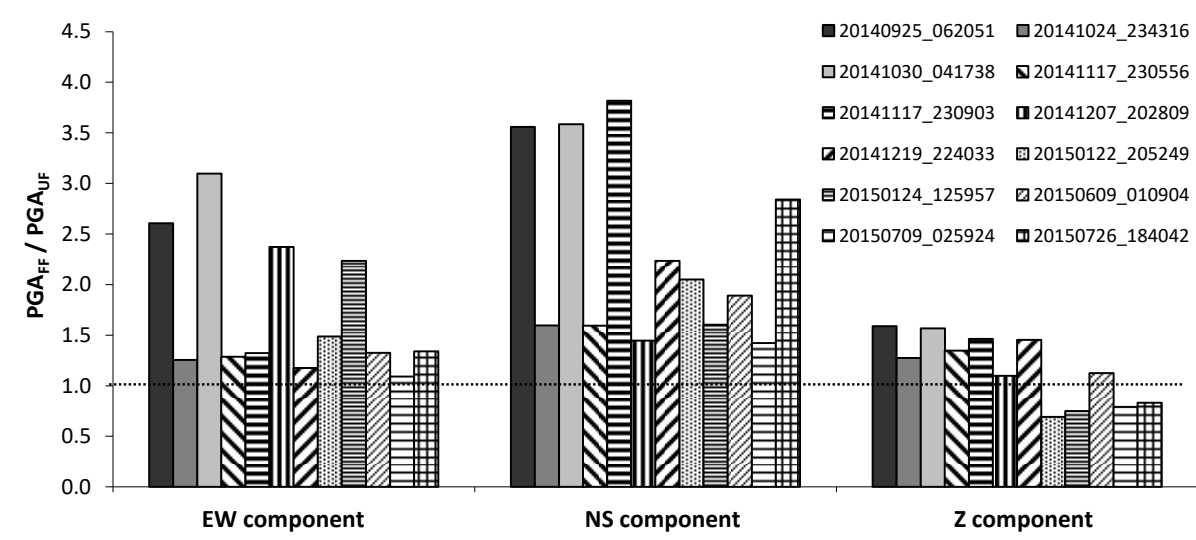

Figure 6 - Peak ground acceleration ratios (PGAFF/PGAuf) of free-field station (KLH7) recordings to urban reference station (KLH4) recordings in the residential sub-zone. Plots refer to the $\mathrm{N}-\mathrm{S}$, the $\mathrm{E}-\mathrm{W}$ and the vertical component of motion as recorded from nine earthquake events.
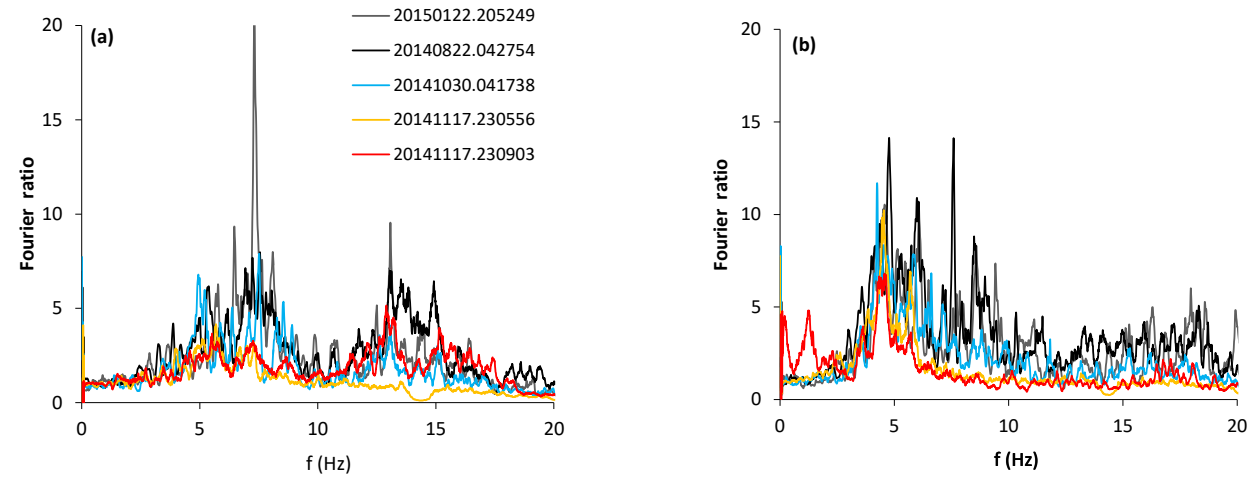

Figure 7 - Structural top-to-ground base Fourier ratios obtained from acceleration recordings of KLH3 ("S" type) and KLH4 ("UF" type) stations in the residential sub-zone:

(a) E-W component (b) N-S component.

The reduced amplitude of acceleration recorded in the urban areas with respect to the free-field zone could possibly indicate a contamination of ground motion due to multiple interactions between soil and structures, as asserted in the review paper of Bard et al. (2007). However, further research in the area of Kalochori is necessary to strengthen the above preliminary observation. 
In the same sense, accelerations recordings from KLH3 ("S" type) and KLH4 ("UF" type) stations in the residential sub-zone were represented in the frequency domain to derive structural top-toground base Fourier ratios, allowing for a preliminary identification of the fundamental vibrational characteristics of the instrumented structure housing the Cultural Centre of Kalochori. Possible soilstructure interaction effects due to the compliance of the foundation soil are by definition taken into account during the procedure since they are inherently imprinted in the recorded motions. The Fourier ratios plotted in Figure 7 refer to the E-W and N-S component of motion recorded from five earthquakes. Results show an evident similarity between the different earthquakes with respect to the frequency range of the first peak that is observed at $7-8 \mathrm{~Hz}$ in the E-W component of motion (Figure 7a). Interpretation of the above similarity should take into account that the earthquakes recorded so far refer to low inertial seismic forces represented by peak accelerations in the range of 5 to $10 \mathrm{mg}$ were imposed on the instrumented building, indicating a linear elastic response of the structure. The frequency range of the first peak obtained for the N-S component (Figure 7b) is shifted to lower frequencies $(4-5 \mathrm{~Hz})$ with respect to the E-W component, denoting a more flexible loadresisting system of the structure along the $\mathrm{N}-\mathrm{S}$ direction. Of course, as already mentioned, these observations should be viewed as a preliminary assessment of the structural mode response under the specific earthquake motions. In this regard, an enriched database of earthquake recordings is foreseen to provide further support on the above issues.

\section{Conclusions}

A focused accelerometric network installed in the complex urban landscape of Kalochori, located west of Thessaloniki, was presented as part of a multi-sensor network within the recently completed INDES-MUSA research project (www.indes-musa.gr) for monitoring seismic motion and ground subsidence in the above area. The INDES-MUSA accelerometric network includes ground installations on both free-field and urban conditions and accelerometric stations on top of structures within different urban sub-zones. Detailed features of the accelerometric stations and the complete set of earthquake recordings that have been acquired so far are reported. Preliminary data interpretation reveals larger peak ground accelerations in the free-field station with respect to the urban ground stations and allows a first-level identification of the frequency range of resonance for the instrumented structures.

\section{Acknowledgments}

The INDES-MUSA project is funded by the General Secretariat for Research and Technology (GSRT) under the framework of the Operational Programme "Competitiveness and Entrepreneurship", Greece - China Bilateral RandTD Cooperation. The authors would like to thank the technical and IT staff of EPPO-ITSAK, Apostolos Marinos, Nikolaos Adam and Kiriaki Konstantinidou for their contribution in the installations and the acquisition of earthquake recordings. Administrative and technical support provided by the Municipality of Delta and the EL.PE Oil Company is also acknowledged.

\section{References}

Bard, P.-Y., Gueguen, P., Chazelas, J.L., Kham, M. and Semblat, J.F., 2007. Seismic hazard in urban environments: Can man modify the hazard? Proc. 3er Congreso Nacional de Ingeniera Sismica, Girona, 8-11 May.

Capon, J., 1969. High-resolution frequency-wavenumber spectrum analysis, Proc. IEEE, 57(8), 1408-1418, doi: 10.1109/PROC.1969. 7278.

Celebi, M., 2003. Identification of site frequencies from building records, Earthquake Spectra, 19(1), 1-23.

Charalampopoulou, B., Manesis, Ch., Tsivikis, K., Savvaidis, A., Makra, K., Ganas, A. and Rovithis, Emm., 2014. 3D city model using LiDAR and digital color imagery in Kalochori 
region, Proc. $1^{\text {st }}$ Intern. Geomatics Application Conference (GEOMAPPLICA), Skiathos, 810 September, 36-43.

Chen, Z., Hutchinson, T.C., Trombetta, N.W., Mason, H.B., Bray, J.D., Jones, K.C. and Fiegel, G.L., 2010. Seismic performance assessment in dense urban environments: evaluation of nonlinear building-foundation systems using centrifuge tests, Proc. $5^{\text {th }}$ International Conference on Recent Advances in Geotechnical Earthquake Engineering and Soil Dynamics, San Diego, California, 24-29 May, paper 5.49a.

COSMOS, 2001. Guidelines for Installation of advanced national seismic system strong motion reference stations, Report, PEER Center, University of California, Berkeley.

Gueguen, P., Bard, P.-Y. and Chavez-Garcia, F.J., 2002. Site-City Seismic Interaction in Mexico City-Like Environments: An Analytical Study, Bulletin of the Seismological Society of America, 92(2), 794-811.

Faccioli, E., Paolucci, R. and Vanini, M., 1996. Studies of site response and soil-structure interaction effects in a tall building in Mexico city, Proc. $11^{\text {th }}$ World Conference on Earthquake Engineering, Acapulco, Mexico.

Horike, M., 1985. Inversion of phase velocity of long-period microtremors to the S-wave-velocity structure down to the basement in urbanized areas, Journal of Physics of the Earth, 33, 59-96.

Kvaerna, T. and Ringdahl, F., 1986. Stability of Various f-k Estimation Techniques, Semiannual Technical Summary (1 October 1985 - 31 March 1986), NORSAR Scientific Report, 1-86/87 (Kjeller, Norway), 29-40.

Lacoss, R.T., Kelly, E.J. and Toksoz, M.N., 1969. Estimation of Seismic Noise Structure Using Arrays, Geophysics, 34, 21-38.

Meli, R., Faccioli, E., Muria-Vila, D., Quaas, R. and Paolucci, R., 1998. A study of site effects and seismic response of an instrumented building in Mexico city, Journal of Earthquake Engineering, 2(1), 89-111.

Nikolaou, S. and Nikolaidis, M., 1987. Geoelectric study in Kalochori village of Thessaloniki. Report, Report, Institute of Geology and Mineral Exploration, Athens, $10 \mathrm{pp}$.

Okada, H., 2003. The Microtremor Survey Method, Society of Exploration Geophysics (SEG), 135 pp.

Paradisopoulou, P.M., Karakostas, V.G., Papadimitriou, E.E., Tranos, M.D., Papazachos, C.B. and Karakaisis, G.F., 2006. Microearthquake study of the broader Thessaloniki area (Northern Greece), Annals of Geophysics, 49(4/5), 1081-1093.

Rovithis, Emm., Charalampopoulou, B., Ganas, A., Savvaidis, A., Makra, K., Konstantinidou, K., Kirtas, Emm., Karakostas, Ch., Lekidis, V., Pitilakis, D., Loupasakis, C., Tsimi, Ch. and Manesis, Ch., 2014. INDES-MUSA Project - Integrated monitoring of subsiding coastal areas prone to large earthquakes: the case of Kalochori in Greece, Proc. $2^{\text {nd }}$ European Conference on Earthquake Engineering and Seismology, Istanbul, 24-29 August, paper No. 2739.

Savvaidis, A., Makra, K. and Rovithis, Emm., 2014 INDES-MUSA project: Geotechnical and geophysical data in the Kalochori area, Report submitted to the General Secretariat of Research and Technology (GSRT), April 2014, 20 pp.

Taborda, R. and Bielak, J., 2011. Large-scale earthquake simulation: Computational seismology and complex engineering systems, Computing in Science and Engineering, 1(1), 14-26.

Wathelet, M., Jongmans, D. and Ohrnberger, M., 2004. Surface-Wave Inversion Using a Direct Search Algorithm and its Application to Ambient Vibration Measurements, Near Surface Geophysics, 2, 211-221.

Wathelet, M., 2005. Array Recordings of Ambient Vibrations: Surface-Wave Inversion, PhD Thesis, University of Liège (Belgium), $177 \mathrm{pp}$. 